\title{
BMJ Open Secondhand smoke exposure (SHS) and health-related quality of life (HRQoL) in Chinese never smokers in Hong Kong
}

\author{
Jing Chen, ${ }^{1}$ Man-Ping Wang, ${ }^{1}$ Xin Wang, ${ }^{2}$ Kasisomayajula Viswanath, ${ }^{3}$ \\ Tai-Hing Lam, ${ }^{2}$ Sophia S Chan ${ }^{1}$
}

To cite: Chen J, Wang M-P, Wang $X$, et al. Secondhand smoke exposure (SHS) and health-related quality of life (HRQoL) in Chinese never smokers in Hong Kong. BMJ Open 2015;5:e007694. doi:10.1136/bmjopen-2015007694

- Prepublication history for this paper is available online. To view these files please visit the journal online (http://dx.doi.org/10.1136/ bmjopen-2015-007694)

Received 16 January 2015 Revised 31 July 2015 Accepted 11 August 2015

CrossMark

\footnotetext{
${ }^{1}$ School of Nursing, The University of Hong Kong, Hong Kong SAR, China ${ }^{2}$ School of Public Health, The University of Hong Kong, Hong Kong SAR, China

${ }^{3}$ Center for Community-Based Research, Dana-Farber Cancer Institute/Department of Social and behavioral Sciences, Harvard School of Public Health, Boston, Massachusetts, USA
}

Correspondence to Dr Tai Hing Lam; hrmrlth@hku.hk

\section{ABSTRACT}

Objective: The evidence on the effect of secondhand smoke (SHS) on Health Related Quality of Life $(\mathrm{HRQOL})$ is limited. We examined the relation between SHS and HRQOL among Chinese in Hong Kong.

Methods: Adult never smokers from a probability sample of three cross-sectional waves (2010, 2012 , 2013) of The Hong Kong Family and Health Information Trends Survey who completed the Cantonese-version of Short-Form 12 Health Survey Questionnaire (SF12v2) were included in the data analysis conducted in 2014. Models were used to examine associations of SHS with SF12 domains and summary scores of Physical (PCS12) and Mental Component (MCS12) with subgroups analysis by SHS locations.

Results: After adjustments, SHS was associated with lower scores on all SF12 domains except physical functioning. PCS12 (regress coefficient=-0.76, 95\% Cl -1.34 to -0.17 ) and MCS12 (regress coefficient= $-1.35,95 \% \mathrm{Cl}-2.06$ to -0.64$)$ were lower in those with SHS exposure than those non-exposed. Those exposed to SHS in outdoor public places had lower scores on most SF12 domains and PSC12 and MCS12. SHS exposure in one's home and workplace was associated with lower scores on role physical, body pain and role emotional while SHS exposure in friends' homes was additionally associated with lower social functioning and mental health scores. Lower MCS12 was associated with SHS exposure at all locations except one's home.

Conclusions: Our study showed that SHS exposure, particularly in outdoor public places, was associated with decreased HRQoL. It can provide new evidence for stronger smoke-free policies on public places and promoting smoke-free homes.

\section{INTRODUCTION}

Worldwide, more than 0.6 million premature deaths and 10.9 million disability-adjusted life years (DALYs) lost in never smokers were attributable to secondhand smoke (SHS) in 2004. ${ }^{1}$ SHS exposure causes lung cancer,

\section{Strengths and limitations of this study}

- Little is known about the effect of secondhand smoke (SHS) on Health Related Quality of Life (HRQoL). This study filled in the gap.

- This study extensively examined associations of SHS with SF12 eight domains and summary scores of Physical (PCS12) and Mental Component (MCS12), with subgroups analysis by SHS locations.

- This study was based on a large representative Chinese sample in Hong Kong with adjustment for many potential confounders.

- SHS exposure was self-reported which could lead to misclassification of true exposure.

- Mental health status at baseline was not adjusted due to the lack of data.

- The duration and intensity of SHS exposure were not recorded in our study. This precluded analysis on dose-response relationship.

coronary heart disease and stroke in adult never smokers, and sudden infant death syndrome and respiratory disorders in infants and children. ${ }^{2} 3$ Cognitive impairment in adult never smokers, ${ }^{4}$ and cognitive and behavioural disorders in children and adolescents were recently found to be associated with SHS exposure. ${ }^{5} 6$

Health-related quality of life (HRQoL) is a comprehensive measurement of physical, social and mental functions and has been used to estimate the impact of chronic disease, ${ }^{78}$ identify health disparities in population, ${ }^{9}$ and inform policies and patient management. ${ }^{7}$ HRQoL is also an important predictor of mortality and morbidity. ${ }^{10-15}$ However, the evidence on the effect of SHS on HRQoL is limited.

Among the few reports on the association between SHS and mental health, most focused on the relation between SHS exposure and psychological distress in adult never smokers, ${ }^{16-18}$ and mental disorders and 
cognitive impairment in non-smoking children and adolescents. ${ }^{561920}$ Studies that examined the association between SHS exposure and physical functioning were mostly restricted to patient samples with inconclusive findings. ${ }^{21-23}$ To our best knowledge, only one study examined the association between SHS exposure and HRQoL in the Swiss general population, which showed that SHS was associated with a significant decrease in HRQoL scores with a dose-response relationship. ${ }^{24}$

Hong Kong is the most economically developed city of China with the most stringent tobacco control policy including comprehensive smoke-free legislation, raising tobacco tax, banning tobacco advertisings and promotions, and providing smoking cessation services. The prevalence of daily smokers decreased from $23.3 \%$ in 1982 to $10.7 \%$ in 2012. ${ }^{25}$ Smoking was banned in public indoor areas (since 1998), indoor restaurants and workplaces (2007), and was further extended to include all entertainment premises (2009) and open-air public transport interchanges and bus terminals (2010). Despite these strong tobacco control measures and the lowest smoking prevalence in the developed world, ${ }^{26}$ SHS exposure is still common in Hong Kong varied in locations designated to be smokefree $(12.3 \%$ workers reported SHS exposure in indoor areas of workplace ${ }^{27}$ ) and locations not yet smoke-free (79.2\% adolescents reported SHS exposure outside home $^{28}$ ). As there is no safe level of SHS exposure, and HRQoL is an important health outcome for evaluating the implementation of policies and predicting morbidity and mortality, this study aimed to investigate (1) the association between SHS exposure and HRQoL among never smokers using a representative Chinese sample, and (2) the association between different locations of SHS exposure and HRQoL.

\section{METHODS}

Study design

The Hong Kong Family and Health Information Trends Survey (FHinTs) was a regular cross-sectional telephone survey (about once every 12-18 months) on a representative sample of the general population living in the households. The first four waves were conducted in 2009 (November-December), 2010/2011 (December-March), 2012 (August-October) and 2013 (October-December). Details of the survey and the representativeness of the sample have been described previously. ${ }^{29}$ In brief, Cantonese-speaking individuals aged 18 and above were recruited in each survey by a 2 -stage random sampling method. Computer assisted telephone interviews based on a structured questionnaire were conducted on eligible participants (one selected by the 'next birthday' method) who had provided oral consent. In total, 6050 participants completed the questionnaire in the 4 waves. As information on SHS exposure was not included in 2009 survey $(\mathrm{n}=1510)$, the present study used data from the 2010 $(\mathrm{n}=1506), 2012 \quad(\mathrm{n}=1537)$ and $2013 \quad(\mathrm{n}=1502)$ surveys.
Current and ex-smokers were excluded from the present analysis $(\mathrm{n}=682)$ and 3861 never smoking participants remained for analysis.

\section{Exposure to SHS}

Self-reported SHS exposure was assessed by the question: Have you been exposed to SHS by any chance? '(yes/ no)'. Participants who answered 'yes' to the first question were classified as with SHS exposure. Multiple choice of locations of SHS exposure were recorded including: one's own home, friends' homes, outdoor areas of the workplace, public leisure places and other public places (eg, streets, bus stops).

\section{HRQOL assessment}

The Cantonese version of Short Form 12 Health Survey Questionnaire (SF12v2) was used to assess HRQoL. SF12v2 has been used in general population surveys in other countries ${ }^{30-35}$ and the Cantonese version has been validated in Hong Kong population. ${ }^{36}$ The instrument has eight domains that is, Physical Functioning, Role Physical, Bodily Pain, General Health, Vitality, Social Functioning, Role Emotional, and Mental Health. The scores for eight domains were standardised to each range from 0-100. Two summary scores of Physical Component (PCS12) and Mental Component (MCS12), each ranging from 0 to 100 , were calculated from the eight domains by applying scoring algorithms with weighted item responses, with higher scores indicating better perceived HRQoL. ${ }^{37}$

\section{Socio-demographic characteristics and health-related behaviours}

Information recorded also included socioeconomic status and health-related behaviours and status including physical activity, presence of physician diagnosed chronic conditions, and weight and height.

\section{Statistical analysis}

The characteristics of the participants with and without SHS exposure were compared using $\chi^{2}$ test. Univariate and multivariable linear regression models were used to examine the association of SHS exposure with SF12 domains, PCS12 and MCS12. Demographic variables and potential confounding factors were adjusted in the models, including age, sex, employment status (employed or not), education (highest level attained), body mass index (BMI, weight in kilograms divided by height in square metres), physical activity (moderate or vigorous physical activities at least once or not in the past 7 days), and self-reported physician diagnosed chronic conditions (any chronic disease, high cholesterol, hypertension, diabetes, bronchitis, hepatitis B, coronary heart disease, asthma, stroke, cancer, and allergic rhinitis). The survey year was also included to adjust for the possible time effect. All the analyses were based on complete cases, as only age, employment status, physical activity and BMI with $0.39 \%, 0.08 \%, 0.13 \%$ and $4.8 \%$ 
Table 1 Prevalence of secondhand smoke (SHS) exposure in never smokers

\begin{tabular}{|c|c|c|c|c|}
\hline & $\mathbf{n}$ & SHS $\%(95 \% \mathrm{Cl})$ & No SHS \% $(95 \% \mathrm{Cl})$ & p Value ${ }^{\star}$ \\
\hline Total & 3807 & 74.8 (73.3 to 76.2 ) & 25.2 (23.8 to 26.7 ) & \\
\hline Age & & & & $<0.001$ \\
\hline $18-24$ & 426 & 85.3 (81.6 to 88.4$)$ & 14.7 (11.6 to 18.4$)$ & \\
\hline $25-44$ & 1435 & 79.9 (77.1 to 82.5$)$ & 20.1 (17.5 to 22.9$)$ & \\
\hline $45-64$ & 1381 & 71.5 (69.2 to 73.6$)$ & 28.5 (26.4 to 30.8$)$ & \\
\hline $65+$ & 551 & 60.9 (57.1 to 64.5$)$ & 39.1 (35.5 to 42.9 ) & \\
\hline Sex & & & & 0.005 \\
\hline Male & 1478 & 77.5 (75.0 to 79.9$)$ & 22.5 (20.1 to 25.0$)$ & \\
\hline Female & 2329 & 73.0 (71.1 to 74.8$)$ & 27.0 (25.2 to 28.9$)$ & \\
\hline Highest education attained & & & & 0.017 \\
\hline Primary or below & 516 & 69.6 (66.0 to 73.0$)$ & 30.4 (27.0 to 34.0 ) & \\
\hline Secondary & 1741 & 75.8 (73.6 to 77.8$)$ & 24.2 (22.2 to 26.4$)$ & \\
\hline Post-secondary & 1548 & 75.4 (72.8 to 77.8$)$ & 24.6 (22.2 to 27.2$)$ & \\
\hline Employment & & & & $<0.001$ \\
\hline Employed & 2188 & $79.2(77.2$ to 81.1$)$ & 20.8 (18.9 to 22.8 ) & \\
\hline Unemployed & 1620 & 68.7 (66.5 to 70.8$)$ & 31.3 (29.2 to 33.5$)$ & \\
\hline Physical activity (days) $\dagger$ & & & & 0.01 \\
\hline 0 & 1141 & 71.8 (69.0 to 74.5$)$ & 28.2 (25.5 to 31.0$)$ & \\
\hline$\geq 1$ & 2663 & 76.0 (74.2 to 77.7$)$ & 24.0 (22.3 to 25.8$)$ & \\
\hline Diagnosed chronic diseases & & & & $<0.001$ \\
\hline No & 2571 & 76.6 (74.8 to 78.4$)$ & 23.4 (21.6 to 25.2$)$ & \\
\hline Yes & 1236 & 70.9 (68.3 to 73.3$)$ & 29.1 (26.7 to 31.7$)$ & \\
\hline
\end{tabular}

missing data respectively. The overall sample was weighted by sex and age from the census data in the year of each wave of the survey. Similar analyses were replicated to assess the effect of the locations of SHS exposure on HRQoL. The significance level was set as $\mathrm{p}<0.05$ and all analyses were performed using STATA (StataCorp. 2013. Stata Statistical Software: Release V.13. College Station, Texas, USA: StataCorp LP). Data analysis was done in July 2014.

\section{Ethical statement}

Ethical approval of the survey was granted by Institutional Review Board (IRB) of the University of Hong Kong/Hospital Authority Hong Kong West Cluster. Since it was a telephone survey, verbal informed consent was obtained from all participants and recorded verbatim. The procedure was approved by the IRB (UW 09-324).

\section{RESULTS}

SHS exposure

Seventy-five per cent (95\% CI 73.3 to 76.2$)$ were exposed to SHS (table 1).

Exposure to SHS was more frequent in younger adults, males, employed participants and those with higher educational level. Those who had more physical activity and no chronic conditions had more SHS exposure.

More females were exposed to SHS at home than males while more males were exposed to SHS at work (table 2). However, there was no significant interaction between sex and any SHS exposure using the interaction term $($ sex $\times$ SHS $)$, and between sex and SHS exposure at different locations (table 3 ).

\section{SHS exposure and SF-12 scores}

Males with SHS exposure had significantly lower (meaning worse) scores on bodily pain and role

Table 2 Secondhand smoke (SHS) exposure in never smokers at different locations by sex ${ }^{*}$

\begin{tabular}{|c|c|c|c|c|}
\hline Locations & Male & Female & Total & p Valuet \\
\hline Own homes & $104(7.0)$ & $342(14.7)$ & $446(11.7)$ & $<0.001$ \\
\hline Friends' homes & $235(16.0)$ & $338(14.5)$ & $573(15.1)$ & 0.30 \\
\hline Workplaces & 720 (48.9) & 900 (38.9) & $1620(42.8)$ & $<0.001$ \\
\hline Outdoor leisure places (eg, parks) & $724(49.0)$ & $1071(46.1)$ & 1795 (47.3) & 0.12 \\
\hline Other public places (eg, bus stops) & $1065(72.0)$ & $1624(69.7)$ & 2689 (70.6) & 0.17 \\
\hline
\end{tabular}


Table 3 Tests of interaction between secondhand smoke (SHS) exposure and sex

\begin{tabular}{lllll}
\hline SHS exposure Locations & $\begin{array}{l}\text { PCS12 coefficient } \\
\text { of the interaction term }\end{array}$ & $\mathbf{p}$ Value & $\begin{array}{l}\text { MCS12 coefficient } \\
\text { of the interaction term }\end{array}$ & $\mathbf{p ~ V a l u e}$ \\
\hline Any SHS exposure & $0.1(-1.2$ to 1.4$)$ & 0.89 & $-0.3(-1.9$ to 1.3$)$ & 0.71 \\
One's own home & $-1.7(-3.5$ to 0.1$)$ & 0.06 & $0.5(-2.0$ to 2.9$)$ & 0.72 \\
Friends' home & $-0.2(-1.6$ to 1.3$)$ & 0.82 & $-1.9(-3.8$ to 0.03$)$ & 0.053 \\
Workplace & $-0.5(-1.6$ to 0.5$)$ & 0.34 & $-0.1(-1.5$ to 1.2$)$ & 0.85 \\
Outdoor leisure places & $-0.1(-1.2$ to 1.0$)$ & 0.87 & $0.2(-1.1$ to 1.6$)$ & 0.76 \\
Outdoor public places & $0.1(-1.2$ to 1.3$)$ & 0.93 & $0.2(-1.3$ to 1.7$)$ & 0.82 \\
\hline Results were weighted by age and sex from census data.
\end{tabular}

emotional domains than those unexposed, whereas nonsignificantly lower scores were found for all the other domains except physical functioning (table 4). In females, significantly lower scores were observed on all domains except physical functioning. SHS exposure was associated with lower PCS12 and MCS12 in females but not males.

After adjustment for potential confounders, SHS exposure at any place was associated with significantly lower scores on all domains (except physical functioning) and for PCS12 (regress coefficient $=-0.76,95 \%$ CI -1.34 to $-0.17, \mathrm{p}=0.011$ ) and MCS12 (regress coefficient $=-1.35,95 \%$ CI -2.06 to $-0.64, \mathrm{p}<0.001) \quad($ table 5 ).

Significantly lower scores were found on role physical and bodily pain domains in those with SHS exposure at all different locations (table 5). Besides, SHS exposure in one's own home was associated with significantly lower scores on role emotional (regress coefficient= $-3.1,95 \%$ CI -5.5 to $-0.6, \mathrm{p}=0.015)$. SHS exposure in friends' homes was associated with lower scores on social functioning (regress coefficient $=-3.3,95 \%$ CI -5.6 to $-0.9, \mathrm{p}=0.007$ ) and mental health (regress coefficient $=-2.2,95 \%$ CI -4.1 to $-0.3, \mathrm{p}=0.027)$. SHS exposure at workplace was associated with lower scores on role emotional (regress coefficient $=-3.3,95 \%$ CI -4.8 to $-1.8, \mathrm{p}<0.001)$. SHS exposure in outdoor public spaces was associated with significantly lower scores on most domains. PCS12 was lower in those with SHS exposure in outdoor leisure and other public places (eg, streets, bus stops). MCS12 was lower in those with SHS exposure at all locations except one's own home.

\section{DISCUSSION}

This study showed that despite strong smoke-free legislation and enforcement and low smoking prevalence in the most westernised Chinese city of Hong Kong, SHS exposure in never smokers was prevalent in Hong Kong particularly in outdoor public places where $70 \%$ were exposed to SHS. SHS exposure was significantly associated with poorer scores on almost all domains of HRQoL and both physical and mental components, independent of other known risk factors such as physical inactivity and physician diagnosed chronic conditions.

Table 4 Age-adjusted SF-12 mean scores $(95 \% \mathrm{Cl})$ by sex and secondhand smoke (SHS) exposure in never smokers (complete case analysis)

\begin{tabular}{|c|c|c|c|c|c|c|}
\hline & \multicolumn{3}{|l|}{ Male $(n=1161)$} & \multicolumn{3}{|l|}{ Female $(n=2611)$} \\
\hline & Not exposed & Exposed & p Value ${ }^{\star}$ & Not exposed & Exposed & p Value ${ }^{\star}$ \\
\hline $\mathrm{PF} \dagger$ & 93.1 (91.1 to 95.1$)$ & 93.8 (92.7 to 95.0$)$ & 0.52 & 88.8 (87.2 to 90.4$)$ & 87.7 (86.7 to 88.6$)$ & 0.22 \\
\hline $\mathrm{RP} \ddagger$ & 89.3 (86.8 to 91.7$)$ & 88.5 (87.1 to 89.8$)$ & 0.56 & $83.9(82.1$ to 85.8$)$ & $81.2(80.0$ to 82.4$)$ & 0.013 \\
\hline $\mathrm{BP}$ & 89.4 (86.7 to 92.0$)$ & 84.8 (83.2 to 86.4$)$ & 0.005 & 80.4 (78.2 to 82.5$)$ & 77.3 (76.0 to 78.5 ) & 0.020 \\
\hline $\mathrm{GH}$ & 53.0 (49.3 to 56.7$)$ & 50.7 (48.7 to 52.7 ) & 0.29 & 46.2 (43.9 to 48.5$)$ & 43.0 (41.7 to 44.4$)$ & 0.024 \\
\hline VT & 68.7 (65.3 to 72.1$)$ & 68.5 (66.7 to 70.2$)$ & 0.91 & 67.5 (65.3 to 69.6$)$ & 63.7 (62.4 to 65.0$)$ & 0.004 \\
\hline SF & 88.5 (85.8 to 91.2$)$ & 88.0 (86.5 to 89.4$)$ & 0.74 & 87.5 (85.8 to 89.2$)$ & 84.6 (83.5 to 85.7$)$ & 0.005 \\
\hline REß & 87.0 (84.7 to 89.2$)$ & 84.0 (82.6 to 85.3$)$ & 0.026 & 82.8 (81.1 to 84.4$)$ & 80.0 (79.0 to 81.0$)$ & 0.006 \\
\hline $\mathrm{MH}$ & 77.2 (74.8 to 79.5$)$ & 75.2 (73.9 to 76.5$)$ & 0.15 & 76.1 (74.7 to 77.5$)$ & 73.6 (72.7 to 74.5$)$ & 0.004 \\
\hline PCS12 & 51.1 (50.2 to 52.0$)$ & 50.7 (50.3 to 51.2$)$ & 0.46 & $48.3(47.7$ to 49.0$)$ & 47.6 (47.2 to 48.0$)$ & 0.046 \\
\hline MCS12 & 52.0 (50.9 to 53.1$)$ & 51.1 (50.5 to 51.7 ) & 0.16 & 51.7 (51.0 to 52.4$)$ & 50.3 (49.8 to 50.7 ) & 0.001 \\
\hline
\end{tabular}

Results were weighted by age and sex from census data.

${ }^{*} p$ Value comparing respondents with and without SHS exposure; significance was tested by linear regression.

tFour missing in female.

$\ddagger$ Two missing in male, Four missing in female.

$\S$ Four missing in female.

ๆOne missing in female.

BP, Bodily Pain; GH, General Health; MH, Mental Health; PF, Physical Functioning;, RE, Role Emotional; RP, Role Physical; SF, Social Functioning; VT, Vitality. 


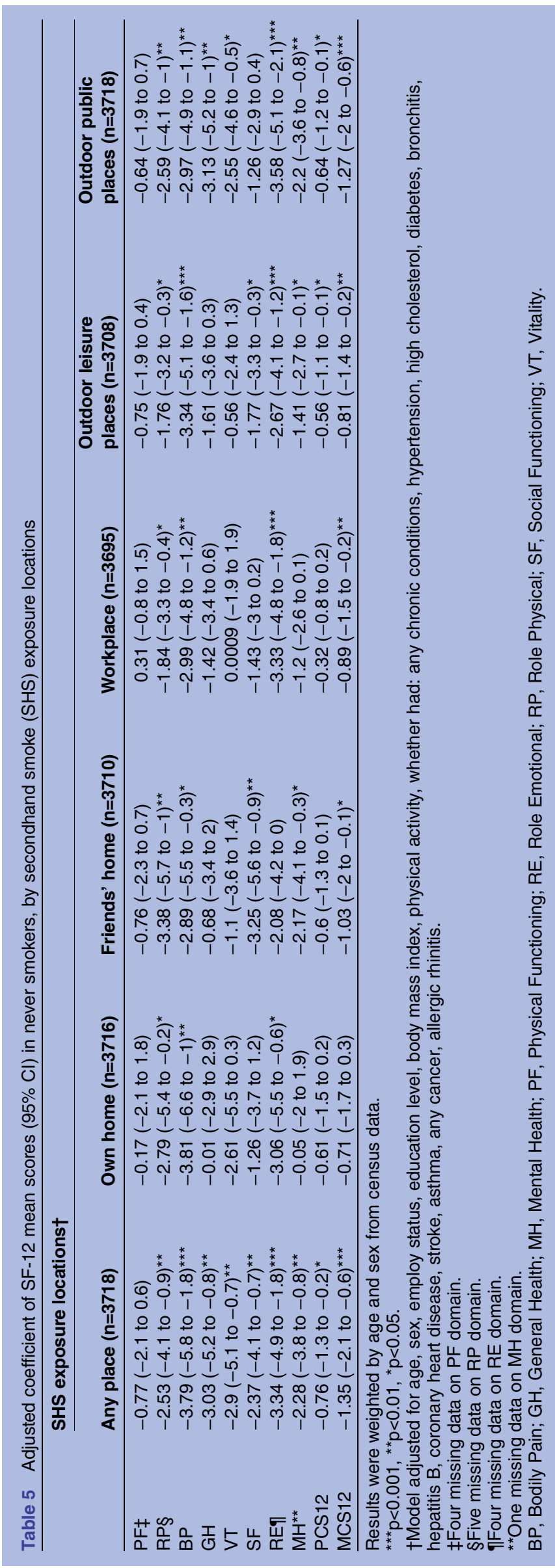

The negative effects of SHS exposure on physical health in never smokers are well-known, ${ }^{38}{ }^{39}$ but little is known about the adverse effects of SHS on mental health. Our findings are consistent with previous studies where higher level of cotinine was associated with poor mental health and depressive symptoms in general adult never smokers. ${ }^{17} 18$ The pathways by which SHS is linked to poor mental health are not sufficiently understood and likely vary. One possibility is that SHS exposure may affect the neurobiological pathways through decreasing dopamine receptor availability which leads to increased risk of depression. ${ }^{40}$ Other possibilities are that poor mental health may be a consequence of impaired physical health (eg, respiratory symptoms) resulting from SHS exposure. ${ }^{41}{ }^{42}$ However, the UK population based study did not find a significant association between objectively measured SHS exposure using exhaled carbon monoxide (CO) and poor mental health. ${ }^{43}$ The lack of association might be due to the limitation of $\mathrm{CO}$ measurement since CO levels increase only slightly and briefly after SHS exposure, and is not a sensitive indicator of SHS exposure.

We found SHS exposure at different locations was consistently associated with poor mental health except for one's own home. Besides the above mentioned possible biological or psychological mechanisms, the association is probably due to the denormalisation of smoking in Hong Kong with the lowest prevalence in the developed world and in China. Smoking is banned in many public places, all indoor workplaces, outdoor leisure places (eg, parks) and public transport interchanges. Involuntary SHS exposure in such places may cause annoyance, transient discomfort and feeling of intrusiveness. People may feel harmed or assaulted when exposed to SHS particularly in places where smoking is banned. Participants who reported SHS exposure at work and in public leisure places (eg, parks) in our study had lower scores on role emotional domain. These lower scores meant that participants feel that they accomplished less than they would like, and worked and did other activities less careful than usual. The negative effect of SHS exposure in friends' homes on mental health was likely due to the high intensity of SHS exposure when gathering with smoking friends. In contrast, exposure to SHS in one's own home did not appear to be associated with poor mental health. This might reflect the feeling of helplessness where people have less control over the external environment than their homes. It may be more difficult to ask friends not to smoke around in friends' homes than to ask them not to smoke in one's own home. ${ }^{41}$ The 'unavoidable' SHS exposure in friends' home may immediately cause disturbance which was reflected by the lower scores on social functioning in our sample where participants with exposure were more likely to feel interfered with their social activities (like visiting friends). Nonetheless, lower scores on role physical and role emotional domains were found in participants exposed to SHS in their own homes which indicated 
their daily life was adversely affected by SHS exposure, even the effect was not reflected in the summary score (MCS12). Our findings if confirmed by prospective studies will support stronger policies to restrict smoking in public places and promote smoke-free homes.

SHS exposure in never smokers particularly in outdoor public places was much more prevalent in Hong Kong compared with other developed countries with strong smoke-free legislations such as the US $(25.3 \%)^{44}$ and UK (16\%). ${ }^{45}$ When smokers are not allowed to smoke indoor and do not quit, they smoke more often in outdoor places and expose more never smokers to their smoke especially in place with a high population density like Hong Kong. A comprehensive smoke-free policy is needed to fully prevent never smokers from SHS exposure. Interestingly, never smokers with higher educational level were more likely to report SHS exposure in our sample, which differed from other findings where SHS exposure was higher in participants with lower educational level. ${ }^{44}{ }^{46}$ Since SHS exposure was self-reported in our study, this anomaly could be explained by that our participants with higher educational level were more aware of SHS and were more sensitive and vocal when exposed. Stronger public health campaigns are needed to raise the awareness of SHS especially in those who are more deprived and more exposed.

Our study had several limitations. First, although many potential confounders had been adjusted in the models, residual confounding cannot be excluded. Although the study design was cross-sectional, reverse causality in which lower HRQoL leading to SHS exposure was unlikely. In contrast, people with low HRQoL might avoid being exposed to SHS which should have resulted in a weaker observed association. Second, mental health status at baseline was not recorded thus not adjusted as a confounder. It might be the case that never smokers with mental illness were disproportionately exposed to SHS which could weaken the observed association. Future studies should also measure knowledge and attitude towards SHS and detail mental health status. Third, SHS exposure was self-reported which could lead to misclassification of true exposure although positive associations between self-reported SHS exposure and SHS exposure measured by biomarkers were frequently reported. ${ }^{42}$ Third, the duration and intensity of SHS exposure were not recorded in our study. This precluded analysis on dose-response relationship, which was suggested by previous studies in Spain $^{20}$ and the US. ${ }^{47}$

Our study was based on a large representative Chinese sample in Hong Kong with adjustment for many potential confounders. The associations, if causal, should have important public health implications. Though comprehensive smoking bans are implemented in indoor workplaces and public places in Hong Kong, the ban on smoking should continue to expand to all public places to prevent SHS exposure to the greatest extent possible. In the future, prospective studies are needed to confirm the causal association to strengthen the policy. Given the predictive power of HRQoL on morbidity and mortality, the effects of policy to reduce SHS exposure in all locations may help prevent premature deaths and reduce mortality, and reduce the disease and economic burden of tobacco use.

In conclusion, our study showed that SHS exposure, particularly in outdoor public places, was associated with decreases in almost all SF12 domains and overall HRQoL. Our findings can provide new evidence for stronger smoke-free policies on public places and promoting smoke-free homes.

Acknowledgements We would like to thank all the subjects who participated in the telephone surveys and the HKU Public Opinion Programme for conducting the fieldwork

Contributors THL, SCC and MPW designed the study. JC, MPW and XW analysed the data. JC and MPW drafted the manuscript. All revised the manuscript.

Funding This study was part of the project 'FAMILY: a Jockey Club Initiative for a Harmonious Society', funded by the Hong Kong Jockey Club Charities Trust. The funder had no role in study design, data collection and analysis, decision to publish, or preparation of the manuscript.

Competing interests None declared.

Ethics approval Ethical approval of the survey was granted by Institutional Review Board (IRB) of the University of Hong Kong/Hospital Authority Hong Kong West Cluster (UW 09-324).

Provenance and peer review Not commissioned; externally peer reviewed.

Data sharing statement No additional data are available.

Open Access This is an Open Access article distributed in accordance with the Creative Commons Attribution Non Commercial (CC BY-NC 4.0) license, which permits others to distribute, remix, adapt, build upon this work noncommercially, and license their derivative works on different terms, provided the original work is properly cited and the use is non-commercial. See: http:// creativecommons.org/licenses/by-nc/4.0/

\section{REFERENCES}

1. Oberg M, Jaakkola MS, Woodward A, et al. Worldwide burden of disease from exposure to second-hand smoke: a retrospective analysis of data from 192 countries. Lancet 2011;377:139-46.

2. US Department of Health and Human Services. The health consequences of involuntary exposure to tobacco smoke: a report of the surgeon general. Atlanta, GA: US Department of Health and Human Services, Centers for Disease Control and Prevention, Coordinating Center for Health Promotion, National Center for Chronic Disease Prevention and Health Promotion, Office on Smoking and Health, 2006.

3. US Department of Health and Human Services. The health consequences of smoking-50 years of progress: a report of the surgeon general. Atlanta, GA: US Department of Health and Human Services, Centers for Disease Control and Prevention, National Center for Chronic Disease Prevention and Health Promotion, Office on Smoking and Health, 2014.

4. Llewellyn DJ, Lang IA, Langa KM, et al. Exposure to secondhand smoke and cognitive impairment in non-smokers: national cross sectional study with cotinine measurement. BMJ 2009;338:b462.

5. Kabir Z, Connolly GN, Alpert HR. Secondhand smoke exposure and neurobehavioral disorders among children in the United States. Pediatrics 2011;128:263-70.

6. Yolton K, Dietrich K, Auinger P, et al. Exposure to environmental tobacco smoke and cognitive abilities among US children and adolescents. Environ Health Perspect 2005;113:98-103.

7. Guyatt GH, Feeny $\mathrm{DH}$, Patrick DL. Measuring health-related quality of life. Ann Intern Med 1993;118:622-9.

8. Jones PW. Health status measurement in chronic obstructive pulmonary disease. Thorax 2001;56:880-7. 
9. Zahran HS, Kobau R, Moriarty DG, et al. Health-related quality of life surveillance--United States, 1993-2002. MMWR Surveill Summ 2005;54:1-35.

10. Kaplan MS, Berthelot JM, Feeny D, et al. The predictive validity of health-related quality of life measures: mortality in a longitudinal population-based study. Qual Life Res 2007;16:1539-46.

11. Otero-Rodriguez A, Leon-Munoz LM, Balboa-Castillo T, et al Change in health-related quality of life as a predictor of mortality in the older adults. Qual Life Res 2010;19:15-23.

12. Osthus AA, Aarstad AK, Olofsson J, et al. Head and neck specific Health Related Quality of Life scores predict subsequent survival in successfully treated head and neck cancer patients: a prospective cohort study. Oral Oncol 2011;47:974-9.

13. Rodriguez-Artalejo F, Guallar-Castillon P, Pascual CR, et al. Health-related quality of life as a predictor of hospital readmission and death among patients with heart failure. Arch Intern Med 2005;165:1274-9.

14. Mapes DL, Lopes AA, Satayathum S, et al. Health-related quality of life as a predictor of mortality and hospitalization: the Dialysis Outcomes and Practice Patterns Study (DOPPS). Kidney Int 2003:64:339-49.

15. Kleefstra N, Landman GW, Houweling ST, et al. Prediction of mortality in type 2 diabetes from health-related quality of life (ZODIAC-4). Diabetes Care 2008;31:932-3.

16. Nakata $A$, Takahashi $M$, Ikeda $T$, et al. Active and passive smoking and depression among Japanese workers. Prev Med 2008;46:451-6.

17. Hamer M, Stamatakis E, Batty GD. Objectively assessed secondhand smoke exposure and mental health in adults: cross-sectional and prospective evidence from the Scottish Health Survey. Arch Gen Psychiatry 2010;67:850-5.

18. Bandiera FC, Arheart KL, Caban-Martinez AJ, et al. Secondhand smoke exposure and depressive symptoms. Psychosom Med 2010;72:68-72.

19. Bandiera FC, Richardson AK, Lee DJ, et al. Secondhand smoke exposure and mental health among children and adolescents. Arch Pediatr Adolesc Med 2011;165:332-8.

20. Padron A, Galan I, Rodriguez-Artalejo F. Second-hand smoke exposure and psychological distress in adolescents. A population-based study. Tob Control 2014;23:302-7.

21. Eisner MD, Balmes J, Yelin EH, et al. Directly measured secondhand smoke exposure and COPD health outcomes. BMC Pulm Med 2006;6:12.

22. Eisner MD, Klein J, Hammond SK, et al. Directly measured second hand smoke exposure and asthma health outcomes. Thorax 2005:60:814-21.

23. Weeks SG, Glantz SA, De Marco T, et al. Secondhand smoke exposure and quality of life in patients with heart failure. Arch Intern Med 2011:171:1887-93.

24. Bridevaux PO, Cornuz J, Gaspoz JM, et al. Secondhand smoke and health-related quality of life in never smokers: results from the SAPALDIA cohort study 2. Arch Intern Med 2007;167:2516-23.

25. Tobacco Control Office, Hong Kong SAR. Pattern of smoking in Hong Kong, 2014. http://www.tco.gov.hk/textonly/english/infostation/ infostation_sta_01.html\#a1 (4 April 2014).

26. Mackay J, Ritthiphakdee B, Reddy KS. Tobacco control in Asia. Lancet 2013;381:1581-7.

27. Census and Statistics Department, Hong Kong SAR. Thematic Household Survey Report, No. 53. Hong Kong, 2013. http://www. censtatd.gov.hk/hkstat/sub/sp140.jsp?productCode=B1130201 (17 September 2014)

28. Wang MP, Ho SY, Lam TH. Parental smoking, exposure to secondhand smoke at home, and smoking initiation among young children. Nicotine Tob Res 2011;13:827-32.

29. Wang MP, Wang X, Lam TH, et al. Health information seeking partially mediated the association between socioeconomic status and self-rated health among Hong Kong Chinese. PLOS ONE 2013;8:e82720

30. Cheak-Zamora NC, Wyrwich KW, McBride TD. Reliability and validity of the SF-12v2 in the medical expenditure panel survey. Qual Life Res 2009;18:727-35.

31. Frieling MA, Davis WR, Chiang G. The SF-36v2 and SF-12v2 health surveys in New Zealand: norms, scoring coefficients and cross-country comparisons. Aust N Z J Public Health 2013;37:24-31.

32. Gandek B, Ware JE, Aaronson NK, et al. Cross-validation of item selection and scoring for the SF-12 Health Survey in nine countries: results from the IQOLA Project. International Quality of Life

Assessment. J Clin Epidemiol 1998;51:1171-8.

33. Kontodimopoulos N, Pappa E, Niakas D, et al. Validity of SF-12 summary scores in a Greek general population. Health Qual Life Outcomes 2007;5:55.

34. Lu L, Zou G, Zeng Z, et al. Health-related quality of life and its correlates among Chinese migrants in small- and medium-sized enterprises in two cities of Guangdong. PLOS ONE 2014;9:e83315

35. Montazeri A, Vahdaninia M, Mousavi SJ, et al. The 12-item medical outcomes study short form health survey version 2.0 (SF-12v2): a population-based validation study from Tehran, Iran. Health Qual Life Outcomes 2011;9:12

36. Lam ET, Lam CL, Fong DY, et al. Is the SF-12 version 2 Health Survey a valid and equivalent substitute for the SF-36 version 2 Health Survey for the Chinese? J Eval Clin Pract 2013;19:200-8.

37. Ware JE. How to score version 2 of the SF-12 health survey (with a supplement documenting version 1). Lincoln, RI: QualityMetric Inc; Boston, Mass.: Health Assessment Lab, 2005.

38. Eisner MD, Wang Y, Haight TJ, et al. Secondhand smoke exposure, pulmonary function, and cardiovascular mortality. Ann Epidemiol 2007:17:364-73.

39. Lai HK, Hedley AJ, Repace J, et al. Lung function and exposure to workplace second-hand smoke during exemptions from smoking ban legislation: an exposure-response relationship based on indoor PM2.5 and urinary cotinine levels. Thorax 2011;66:615-23.

40. Bandiera FC. What are candidate biobehavioral mechanisms underlying the association between secondhand smoke exposure and mental health? Med Hypotheses 2011;77:1009-10.

41. Spangler J, Csakanyi Z, Rogers T, et al. Parental ease in asking others not to smoke and respiratory symptoms and illness among children. Int J Environ Res Public Health 2014;11:1747-55.

42. Okoli CT, Kelly T, Hahn EJ. Secondhand smoke and nicotine exposure: a brief review. Addict Behav 2007:32:1977-88.

43. Lam E, Kvaavik E, Hamer M, et al. Association of secondhand smoke exposure with mental health in men and women: cross-sectional and prospective analyses using the UK Health and Lifestyle Survey. Eur Psychiatry 2013;28:276-81.

44. Homa DM, Neff LJ, King BA, et al. Vital Signs: Disparities in Nonsmokers' Exposure to Secondhand Smoke-United States, 1999-2012. MMWR Morb Mortal Wkly Rep 2015;64:103-8.

45. Bromley C, Dowling S, Gray L, et al. The Scottish Health Survey: A National Statistics Publication for Scotland. 2012 edn. http://www. gov.scot/resource/0043/00434590.pdf (accessed $30 \mathrm{Jul}$ 2015).

46. Wang CP, Ma SJ, Xu XF, et al. The prevalence of household second-hand smoke exposure and its correlated factors in six counties of China. Tobacco Control 2009;18:121-6.

47. Sobotova L, Liu YH, Burakoff A, et al. Household exposure to secondhand smoke is associated with decreased physical and mental health of mothers in the USA. Matern Child Health $J$ 2011;15:128-37. 